\title{
Adherence to complementary feeding recommendations for infants and implications for public health
}

\author{
Suzanne Fegan ${ }^{1, *}$, Emma Bassett ${ }^{1}$, Yingwei Peng ${ }^{2}$ and Kathleen Steel O'Connor ${ }^{1,2}$ \\ 'Knowledge Management, KFL\&A Public Health, 221 Portsmouth Avenue, Kingston, Ontario, Canada, K7M 1V5: \\ ${ }^{2}$ Department of Public Health Sciences, Queen's University, Kingston, Ontario, Canada
}

Submitted 24 October 2014: Final revision received 24 March 2015: Accepted 1 April 2015: First published online 20 May 2015

\begin{abstract}
Objective: The current study investigates (i) the extent to which breast-feeding and non-breast-feeding mothers follow the Canadian Nutrition for Healthy Term Infants (NHTI) recommendations; (ii) the first complementary foods given and the differences by breast-feeding status; (iii) whether any breast-feeding is associated with earlier introduction to complementary foods relative to non-breast-feeding, after controlling for potentially confounding factors; and (iv) the need for improvements in timing and resources of interventions by examining breastfeeding rates over time and information sources used by mothers.

Design: Longitudinal data from the Kingston, Frontenac, and Lennox \& Addington (KFL\&A) Infant Feeding Survey were used. Mothers completed a survey at the end of their hospital stay and were interviewed by telephone at 2, 4, 6 and 12 months thereafter.

Setting: The study took place in the KFL\&A region of Ontario, Canada.

Subjects: The sample consisted of 325 mothers who gave birth to a live infant of at least 36 weeks' gestation and a birth weight of at least $1500 \mathrm{~g}$ at Kingston General Hospital between January and July of 2008.

Results: Four in five mothers introduced complementary foods prior to 6 months. Mothers not breast-feeding at 6 months introduced water, juice, infant cereals, fruit and vegetables, and foods not recommended by Canada's Food Guide sooner than breast-feeding mothers. Breast-feeding mothers were more likely to introduce milks appropriately, but had low adherence to giving their infants vitamin D supplements.

Conclusions: To support adherence to NHTI recommendations, interventions should be conducted during early infancy and deliver consistent, evidence-based recommendations.
\end{abstract}

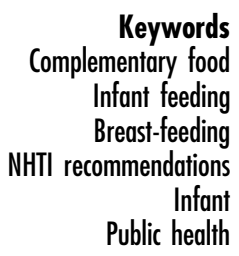

In accordance with the WHO, Health Canada's Nutrition for Healthy Term Infants (NHTI) recommends that infants be exclusively breast-fed during the first 6 months of life ${ }^{(1,2)}$. These recommendations are based on a large body of scientific evidence which indicates that exclusive breast-feeding during this critical period promotes optimal nutrition, immunological protection and growth of the developing infant ${ }^{(1,3)}$. It is also advised that complementary foods, i.e. solid foods and liquids other than breast milk or formula, be avoided during the first 6 months of an infant's life ${ }^{(1,2)}$. The NHTI provides clear recommendations for both the timing of complementary feeding generally and the order in which food groups should be introduced. For example, NHTI recommendations outline optimal first foods and foods to be delayed ${ }^{(3)}$.
Introducing complementary foods before 6 months may increase the risk of adverse health outcomes including diabetes, unhealthy weight status and eczema ${ }^{(4-7)}$. Many studies indicate that breast-fed infants may have a lowered likelihood of obesity later in life ${ }^{(4,8,9)}$, but some inconsistent findings indicate the need for further investigation $^{(9,10)}$. Despite potential health risks, several Canadian and international studies have reported that infants are frequently introduced to complementary foods before 6 months ${ }^{(11-14)}$.

It is important to understand which of the NHTI recommendations require increased support in order for health professionals to best inform caregivers and most effectively design programmes. The public health literature addresses only a few of the published recommendations; in particular, 
exclusive breast-feeding and the timing of complementary food introduction. Many studies demonstrate low rates of exclusive breast-feeding in Canada and other countries, and that both exclusive and partial breast-feeding are associated with later introduction to complementary foods ${ }^{(3,11,15-24)}$ while formula feeding is associated with earlier introduction to complementary foods ${ }^{(15,18,25-27)}$. Fewer studies are available regarding, for example, vitamin D supplementation, the importance of introducing iron-rich foods first and delaying the introduction of honey and certain milks. There is also limited understanding of the extent to which breastfeeding at 6 months, with or without formula supplementation, may be linked to these recommendations. Exploring these issues, as well as gaining an understanding of the order in which particular foods are introduced by breast-feeding and non-breast-feeding mothers, would allow public health initiatives to be tailored to mothers who would most benefit from support.

The current study aimed to address these questions by investigating adherence to the NHTI recommendations, in place at the time of the study, in a sample of mothers from the Kingston, Frontenac, and Lennox \& Addington (KFL\&A) region of Ontario, Canada ${ }^{(28)}$. Mothers who breast-fed to any degree at 6 months and those who exclusively formula-fed were compared with respect to feeding practices and adherence to NHTI recommendations. This comparison was selected over exclusive to non-exclusive breast-feeders to produce results that have more generalizable implications, as low rates of exclusive breast-feeding rates at 6 months are observed in the local maternal population. Similar classification schemes have been used in other research, recognizing that there are immunological benefits to even partial breast-feeding ${ }^{(9,15)}$. To ensure a comprehensive approach in summarizing the relationship between breast-feeding and complementary food introduction, and to control for known confounders, confirmatory analyses were conducted to examine if partial breast-feeding delays the introduction of complementary foods. The current study also examined changes in breast-feeding rates and the sources of infant feeding information that parents accessed as a means to examine potential timing and sources of interventions to promote NHTI recommendations. This thereby enables us to discuss implications directly relevant to public health. Thus, the primary objectives were to:

1. determine the extent to which breast-feeding and non-breast-feeding mothers were following the NHTI recommendations in place at the time of the Infant Feeding Survey;

2. describe first complementary foods and investigate differences by breast-feeding status;

3. confirm whether any breast-feeding is associated with earlier introduction to complementary foods relative to non-breast-feeding, after controlling for potentially confounding factors; and
4. determine needs for improvements in timing and resources of interventions by examining breastfeeding rates over time and information sources used by mothers.

\section{Materials and methods}

\section{Study design}

Data used in the present study came from a subset of mothers who completed the Infant Feeding Survey, which was conducted in 2008 in the KFL\&A region of Ontario, Canada. Maternal characteristics, attitudes and behaviours surrounding infant feeding practices were examined. Women were eligible for the study if they gave birth to a live infant of at least 36 weeks' gestation and a birth weight of at least $1500 \mathrm{~g}$ at Kingston General Hospital between 1 January 2008 and 31 July 2008. Mothers whose infants were admitted to the neonatal intensive care unit were approached to participate in the survey only after their baby was well enough to be discharged from hospital. Only the first born of multiples was included. Of the 1055 women who gave birth to a live infant of eligible gestation and birth weight, 463 (43.9\%) met the Infant Feeding Survey inclusion criteria and agreed to participate, with $325(70 \cdot 2 \%)$ of these mothers providing sufficient information regarding the introduction of complementary foods to be included in the current analysis. All mothers provided informed consent prior to participation. Mothers were asked to complete the initial survey at the end of their hospital stay and were subsequently interviewed by telephone at 2, 4, 6 and 12 months after birth. Follow-up information was linked to the in-hospital survey results to provide individual records for each mother. The study was approved by the Queen's University and Associated Teaching Hospitals Research Ethics Board. All measures came from the KFL\&A Public Health Infant Feeding Survey ${ }^{(29)}$.

\section{Introduction to complementary foods}

Complementary foods were addressed by a twenty-nineitem food questionnaire developed by the Reproductive Health Team at KFL\&A Public Health, which is comprised of public health nurses, managers and a public health dietitian. Mothers were asked at all time points in the study whether or not they had given their infant any of the specified food or drink items more than once. When responses were affirmative, mothers were asked the age of the infant when the item was introduced. Timing of introduction was coded in weeks; for coding purposes each month was considered to be four weeks.

\section{Breast-feeding status}

Breast-feeding status was categorized as 'any breastfeeding' or 'non-breast-feeding'. Mothers were considered 
to be in the any breast-feeding group if they were feeding breast milk to their infant at 6 months, regardless of whether they were exclusively breast-feeding or supplementing with formula and/or complementary foods. The non-breast-feeding group consisted of women exclusively formula-feeding their infant at 6 months, with or without feeding complementary foods. Breast-feeding status was measured at each follow-up interview and breast-feeding trends over the study period were used to address Objective 4 .

\section{Covariates and other measures}

Covariates used during model building included the mothers' age (15-24, 25-34, $\geq 35$ years), education (high school or less, some education after high school, college or university diploma or degree), household income

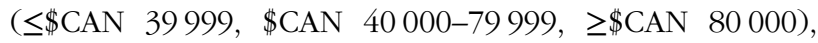
smoking during pregnancy (yes, no), attendance at a breast-feeding or prenatal class (yes, no), parity $(1, \geq 2$ ), prior breast-feeding status (yes or no to breast-feeding a previous child), infant birth weight (1500-2499g, 2500-3999 g, $\geq 4000 \mathrm{~g}$ ) and infant admission to an intensive care unit (yes, no). Given the large number of missing values, 'prior breast-feeding' was excluded from the analysis.

Foods were categorized into groups for analysis. 'Infant cereals' included rice, barley, oat or wheat infant cereals or Pablums ${ }^{\mathrm{TM}}$. 'Other grains' included cooked cereals such as oatmeal, teething biscuits, bread, crackers, breadsticks or unsweetened breakfast cereals, rice and pasta. 'Vegetables and fruit' included vegetables and fruit that were fresh, frozen or in jars or cans, and diluted or undiluted fruit juice. 'Whole milks' referred to whole milk only. 'Other milks' included $2 \%$ fat, $1 \%$ fat, skimmed and chocolate milks, and evaporated, soya and rice milks. 'Milk products' included milk products such as cheese and yoghurt. 'Meats and alternatives' included meats and alternatives such as fish, beans and tofu, and mixed dishes containing meats (stews). Eggs are not included here as the survey did not capture the timing of introduction of this food item. 'Foods not recommended' were foods not recommended by the version of Canada's Food Guide ( $\mathrm{CFG}$ ) in place in $2008^{(30)}$. These foods included sugary drinks such as soft drinks, Kool-Aid ${ }^{\circledR}$ and artificial fruit drinks, processed meats such as hot dogs, and salty or sweet foods like potato chips, candy or chocolate. There is no age at which the foods in this final category are recommended; these foods have little or no nutritional value and may be high in sugar or salt. Infants have high energy needs and small stomachs, and their hunger should not be satiated by foods that do not promote optimal growth and development ${ }^{(31)}$.

Mothers reported the sources they used most frequently to gather information on introducing complementary foods to their infant, as well as the sources they considered most useful. The top five sources accessed and the five rated as most useful for information on introducing complementary foods were used to address Objective 4.

\section{Statistical analysis}

Analyses to address Objectives 1 and 2 included frequencies, cross-tabulations, means and proportions. Then $\chi^{2}$ tests and one-tailed $t$ tests were conducted to test for significant differences in proportions or means between any breastfeeding and non-breast-feeding groups. For Objective 3, Cox proportional hazards models were used to examine the association between breast-feeding status and time to introduction of complementary foods, while controlling for confounding characteristics. A mother's breast-feeding status can change from any breast-feeding to non-breastfeeding at any time during the follow-up period and thus breast-feeding status was treated as a time-dependent variable. One advantage of using a Cox proportional hazards model is that it allows time-dependent variables as covariates in the model. Even though the proportional hazards assumption is no longer valid with the introduction of time-dependent variables in Cox's model, its estimation method still provides valid estimates ${ }^{(32)}$. Thus, this model can be used to assess the effect of the timedependent breast-feeding status on time to introduction of complementary foods. Using a critical value of $P=0 \cdot 25$, the sociodemographic, infant and maternal characteristics to be included in the final model were determined. Based on this criterion, infant admission to an intensive care unit, household income and maternal education level were not included in the final model. The final Cox proportional hazards model examines the association between breastfeeding status (as a time-varying covariate) and time to introduction of complementary foods after controlling for mother's age, parity, smoking history, attendance at prenatal classes and infant birth weight. Hazard ratios and $95 \%$ confidence intervals are reported and a $P$ value of $<0.05$ was considered statistically significant. To investigate Objective 4 , life-table analyses and frequencies were conducted to examine breast-feeding trends and reported sources of infant feeding information, respectively. All statistical analyses were conducted using the statistical software package Stata version 11 (2009).

\section{Results}

\section{Study sample}

Participant retention for the Infant Feeding Survey was $82 \%$ ( $n$ 379) at 2 months, $75 \%(n$ 348) at 4 months, $71 \%$ ( $n$ 330) at 6 months and $65 \%(n$ 302) at 12 months. For the purposes of the present paper, mothers who gave adequate information on the introduction of complementary foods to their infant on one of the 4-, 6- or 12-month surveys were included in the analysis ( $n$ 325). To be included, information regarding the introduction of both iron-rich foods and other foods recommended by CFG was required. 
Table 1 Characteristics of the study sample according to breast-feeding status; Kingston, Frontenac, and Lennox \& Addington (KFL\&A) Infant Feeding Survey, Ontario, Canada, 2008

\begin{tabular}{|c|c|c|c|c|c|c|}
\hline & \multicolumn{2}{|c|}{ All mothers } & \multicolumn{2}{|c|}{$\begin{array}{l}\text { Any breast-feeding at } \\
6 \text { months }\end{array}$} & \multicolumn{2}{|c|}{$\begin{array}{l}\text { Non-breast-feeding at } \\
6 \text { months }\end{array}$} \\
\hline & $\%$ & $n$ & $\%$ & $n$ & $\%$ & $n$ \\
\hline Mother's age $^{\star *}$ & \multicolumn{2}{|c|}{$n 320$} & \multicolumn{2}{|c|}{$n 164$} & \multicolumn{2}{|c|}{$n 155$} \\
\hline $15-24$ years & $14 \cdot 4$ & 46 & 7.9 & 13 & $21 \cdot 3$ & 33 \\
\hline $25-34$ years & $66 \cdot 6$ & 213 & 68.3 & 112 & 64.5 & 100 \\
\hline$\geq 35$ years & $19 \cdot 1$ & 61 & $23 \cdot 7$ & 39 & $14 \cdot 2$ & 22 \\
\hline Mother's education** & \multicolumn{2}{|c|}{$n 320$} & \multicolumn{2}{|c|}{$n 164$} & \multicolumn{2}{|c|}{$n 155$} \\
\hline High school or less & $10 \cdot 9$ & 35 & 5.5 & 9 & $16 \cdot 1$ & 25 \\
\hline $\begin{array}{l}\text { Some post-secondary or college/university } \\
\text { diploma or degree }\end{array}$ & $89 \cdot 1$ & 285 & 94.5 & 155 & 83.9 & 130 \\
\hline Household income $e^{\star \star \star}$ & \multicolumn{2}{|c|}{$n 286$} & \multicolumn{2}{|c|}{$n 148$} & \multicolumn{2}{|c|}{$n 137$} \\
\hline$\leq$ SCAN 39999 & $19 \cdot 9$ & 57 & 14.9 & 22 & 24.8 & 34 \\
\hline \$CAN 40 000-79999 & 33.2 & 95 & $27 \cdot 0$ & 40 & $40 \cdot 1$ & 55 \\
\hline$\geq \$ C A N 80000$ & $46 \cdot 9$ & 134 & $58 \cdot 1$ & 86 & $35 \cdot 0$ & 48 \\
\hline Parity & \multicolumn{2}{|c|}{ n 317} & \multicolumn{2}{|c|}{$n 164$} & \multicolumn{2}{|c|}{$n 152$} \\
\hline 1 child & $49 \cdot 2$ & 156 & $46 \cdot 0$ & 77 & $52 \cdot 0$ & 79 \\
\hline$\geq 2$ children & $50 \cdot 8$ & 161 & 53.0 & 87 & 48.0 & 73 \\
\hline Smoking during pregnancy ${ }^{* \star *}$ & \multicolumn{2}{|c|}{$n 319$} & \multicolumn{2}{|c|}{$n 164$} & \multicolumn{2}{|c|}{$n 154$} \\
\hline Yes & $10 \cdot 3$ & 32 & 3.7 & 6 & $16 \cdot 2$ & 25 \\
\hline No & $90 \cdot 2$ & 287 & $96 \cdot 3$ & 158 & 83.8 & 129 \\
\hline Infant admission to ICU & \multicolumn{2}{|c|}{$n 268$} & \multicolumn{2}{|c|}{$n 138$} & \multicolumn{2}{|c|}{$n 129$} \\
\hline Yes & $7 \cdot 8$ & 21 & $5 \cdot 8$ & 8 & $10 \cdot 1$ & 13 \\
\hline No & $92 \cdot 2$ & 247 & $94 \cdot 2$ & 130 & 89.9 & 116 \\
\hline Infant birth weight & \multicolumn{2}{|c|}{$n 299$} & \multicolumn{2}{|c|}{$n 153$} & \multicolumn{2}{|c|}{$n 145$} \\
\hline $1500-2499 \mathrm{~g}$ & $2 \cdot 7$ & 8 & 1.3 & 2 & $4 \cdot 1$ & 6 \\
\hline $2500-3999 \mathrm{~g}$ & $82 \cdot 3$ & 246 & $80 \cdot 4$ & 123 & $84 \cdot 1$ & 122 \\
\hline$\geq 4000 \mathrm{~g}$ & $15 \cdot 1$ & 45 & $18 \cdot 3$ & 28 & 11.7 & 17 \\
\hline Attendance at breast-feeding or prenatal class ${ }^{\star \star \star}$ & \multicolumn{2}{|c|}{$n 319$} & \multicolumn{2}{|c|}{$n 164$} & \multicolumn{2}{|c|}{$n 154$} \\
\hline Yes & $48 \cdot 3$ & 154 & 38.4 & 63 & $58 \cdot 4$ & 90 \\
\hline No & 51.7 & 165 & 61.6 & 101 & 41.6 & 64 \\
\hline Previously breast-fed an infant ${ }^{\star \star \star}$ & \multicolumn{2}{|c|}{$n 141$} & \multicolumn{2}{|c|}{$n 78$} & \multicolumn{2}{|c|}{$n 62$} \\
\hline Yes & 89.4 & 126 & 97.4 & 76 & $79 \cdot 0$ & 49 \\
\hline No & $10 \cdot 6$ & 15 & $2 \cdot 6$ & 2 & $21 \cdot 0$ & 13 \\
\hline
\end{tabular}

ICU, intensive care unit.

Significant difference between groups: ${ }^{* \star} P<0.01,{ }^{\star * *} P<0.001$.

Characteristics of the study mothers are described in Table 1. Due to some missing responses, sample sizes are presented separately for each variable in the table. Two-thirds of participating mothers were between the ages of 25 and 34 years (66.6\%), the majority had at least some post-secondary education (89.1\%) and $46.9 \%$ reported an annual household income level in excess of \$CAN 80000 . Approximately half of the sample had attended a breast-feeding or prenatal class during pregnancy $(48.3 \%)$ and were first-time mothers (49.2\%). The rate of smoking during pregnancy in the current sample was $9.7 \%$. A total of $7.8 \%$ of infants were reported by their mothers to be admitted to the intensive care unit, and the majority of infants in the sample (82.3\%) weighed between 2500 and $3999 \mathrm{~g}$ at birth. Just over half of mothers, $51.2 \%$, were providing at least some breast milk to their infant at 6 months, but only $6 \cdot 8 \%$ of mothers were exclusively breast-feeding at this time (Table 2). Mothers who were in the any breast-feeding group at 6 months were older, more educated, had a higher total household income, had lower smoking rates, and were more likely to have attended prenatal or breast-feeding classes than mothers who were not breast-feeding at 6 months.
Objective 1: Determine the extent to which breastfeeding and non-breast-feeding mothers were following the Nutrition for Healthy Term Infants recommendations at the time of the Infant

\section{Feeding Survey}

Table 2 presents the proportion of mothers who followed the NHTI recommendations that could be addressed using the Infant Feeding Survey data. Proportions are provided for the whole sample, as well as by the breast-feeding status of the mother. Since data for the current study were collected in 2008, NHTI recommendations available to mothers in 2008 were included in the table ${ }^{(28)}$. The proportion of mothers who adhered to the recommendations ranged from $1.8 \%$ to $96.0 \%$, depending on the particular recommendation(s) under investigation. Only six mothers (1.8\%) followed all the recommendations listed in Table 2. Ten mothers ( $4.9 \%)$ followed all the recommendations, except that they supplemented with formula prior to 6 months. Twenty-two mothers (6.8\%) exclusively breastfed to 6 months.

With regard to the overall introduction of solids and liquids, $19 \cdot 4 \%$ of mothers followed Recommendation 22 and did not introduce complementary foods before 
Table 2 Proportion of mothers who followed the NHTI recommendations ${ }^{(28)}$ according to breast-feeding status; Kingston, Frontenac, and Lennox \& Addington (KFL\&A) Infant Feeding Survey, Ontario, Canada, 2008

\begin{tabular}{|c|c|c|c|c|}
\hline \multirow[b]{2}{*}{ Recommendation } & \multirow[b]{2}{*}{ Indicator } & \multicolumn{3}{|c|}{ Frequency followed (\%) } \\
\hline & & $\begin{array}{c}\text { All } \\
\text { mothers } \\
(n 325)\end{array}$ & $\begin{array}{l}\text { Any breast- } \\
\text { feeding at } \\
6 \text { months } \\
(n 166)\end{array}$ & $\begin{array}{l}\text { Non-breast- } \\
\text { feeding at } \\
6 \text { months } \\
(n 158)\end{array}$ \\
\hline $\begin{array}{l}\text { Recommendation 1: Encourage exclusive breast- } \\
\text { feeding for the first } 6 \text { months of life, as breast milk } \\
\text { is the best food for optimal growth }\end{array}$ & $\begin{array}{l}\text { 1. Exclusively breast-fed at } 6 \text { months } \\
\text { 2. Any breast-feeding: fed some breast milk at } \\
6 \text { months (with or without formula) }\end{array}$ & $\begin{array}{r}6 \cdot 8 \| \\
51 \cdot 2 \|\end{array}$ & $\begin{array}{c}13 \cdot 2 \\
100\end{array}$ & $\begin{array}{l}0 \\
0\end{array}$ \\
\hline \multirow[t]{2}{*}{$\begin{array}{l}\text { Recommendation 22: Nutrient-rich complementary } \\
\text { foods at } 6 \text { months to meet the infant's increasing } \\
\text { nutritional requirements and developmental needs }\end{array}$} & $\begin{array}{l}\text { 3. Water not introduced before } 6 \text { months } \\
\text { 4. Juice not introduced before } 6 \text { months } \\
\text { 5. Water or any other liquids (excluding breast } \\
\text { milk or formula) not introduced before } \\
6 \text { months }\end{array}$ & $\begin{array}{l}59 \cdot 4 \\
85 \cdot 9 \\
54 \cdot 8\end{array}$ & $\begin{array}{l}76 \cdot 5^{\star \star \star} \\
95 \cdot 7^{\star \star \star} \\
74 \cdot 1^{\star \star \star}\end{array}$ & $\begin{array}{l}41 \cdot 8^{\star \star \star} \\
75 \cdot 9^{\star \star \star} \\
34 \cdot 8^{\star \star \star}\end{array}$ \\
\hline & $\begin{array}{l}\text { 6. Solids not introduced before } 6 \text { months } \\
\text { 7. Solids or liquids (excluding breast milk or } \\
\text { formula) not introduced before } 6 \text { months }\end{array}$ & $\begin{array}{l}24 \cdot 3 \\
19 \cdot 4\end{array}$ & $\begin{array}{l}34 \cdot 9^{\star \star \star} \\
31 \cdot 3^{\star \star \star}\end{array}$ & $\begin{aligned} 13 \cdot 3^{* \star *} \\
7 \cdot 0^{* * *}\end{aligned}$ \\
\hline $\begin{array}{l}\text { Recommendation 10: Provide a daily } 10 \mu \mathrm{g}(400 \mathrm{IU}) \\
\text { vitamin } D \text { supplement to all breast-fed infants } \\
\text { starting at birth and until the diet includes at least } \\
10 \mu \mathrm{g}(400 \mathrm{IU}) \text { vitamin } D \text { from other dietary } \\
\text { sources, or until the breast-fed infant reaches } \\
1 \text { year of age }\end{array}$ & $\begin{array}{l}\text { 8. For breast-fed infants: mothers who were } \\
\text { currently providing a vitamin D supplement at } \\
6 \text { months }\end{array}$ & $\mathrm{N} / \mathrm{A}$ & $58 \cdot 4$ & N/A \\
\hline $\begin{array}{l}\text { Recommendation 15: Pasteurized whole cow's milk } \\
\text { may be introduced at } 9 \text { to } 12 \text { months of age and } \\
\text { continued throughout the second year of life }\end{array}$ & 9. Followed Recommendation $15 \ddagger$ & $96 \cdot 0$ & $96 \cdot 9$ & $95 \cdot 0$ \\
\hline $\begin{array}{l}\text { Recommendation 16: Partly skimmed milk ( } 1 \% \text { fat } \\
\text { and } 2 \% \text { fat) is not routinely recommended in the } \\
\text { first } 2 \text { years }\end{array}$ & 10. Followed Recommendations 16 and $17 \ddagger, \S$ & $87 \cdot 7$ & $90 \cdot 7$ & $84 \cdot 2$ \\
\hline $\begin{array}{l}\text { Recommendation 17: Skimmed milk is inappropriate } \\
\text { in the first } 2 \text { years }\end{array}$ & 11. Followed Recommendation $18 \ddagger, \S$ & $92 \cdot 3$ & $94 \cdot 4$ & $88 \cdot 4$ \\
\hline $\begin{array}{l}\text { Recommendation 18: Soya (except soya formula), } \\
\text { rice or other vegetarian beverages, whether or not } \\
\text { they are fortified, are inappropriate alternatives to } \\
\text { breast milk, formula or pasteurized whole cow's } \\
\text { milk in the first } 2 \text { years. Soya milk is only } \\
\text { recommended for infants fed vegan diets and } \\
\text { infants with galactosaemia† }\end{array}$ & $\begin{array}{l}\text { 12. Followed Recommendations } 15,16,17 \text { and } \\
18 \ddagger, \S\end{array}$ & $82 \cdot 4$ & $86 \cdot 4^{\star}$ & $77 \cdot 7^{\star}$ \\
\hline $\begin{array}{l}\text { Recommendation 21: Do not use herbal teas or } \\
\text { other beverages }\end{array}$ & $\begin{array}{l}\text { 13. Followed Recommendation } 21 \text { (did not } \\
\text { introduce soft drinks, Kool-Aid, sugar water, } \\
\text { tea, or artificial fruit drinks before } \\
12 \text { months) } \ddagger, \S\end{array}$ & $95 \cdot 0$ & $98 \cdot 1^{*}$ & $91 \cdot 3^{*}$ \\
\hline $\begin{array}{l}\text { Recommendation 22: Nutrient-rich complementary } \\
\text { foods at } 6 \text { months to meet the infant's increasing } \\
\text { nutritional requirements and developmental needs }\end{array}$ & $\begin{array}{l}\text { 14. Iron-rich foods introduced sooner or at the } \\
\text { same time as other solid food items }\end{array}$ & $92 \cdot 9$ & $95 \cdot 7$ & $90 \cdot 5$ \\
\hline $\begin{array}{l}\text { Recommendation 23: To prevent iron deficiency, } \\
\text { iron-containing foods are recommended as the } \\
\text { first foods } \\
\text { NHTI comment regarding transition to solid foods: } \\
\text { By } 1 \text { year of age, the ingestion of a variety of foods } \\
\text { from the different food groups of CFG is desirable }\end{array}$ & $\begin{array}{l}\text { 15. No introduction of foods in the first } 12 \text { months } \\
\text { not recommended by } \mathrm{CFG}^{(30)} \text { or the NHTI } \\
\text { recommendations }{ }^{(28)} \text { including: other } \\
\text { beverages (soft drinks, Kool-Aid, sugar water, } \\
\text { tea, or artificial fruit drinks), cookies, } \\
\text { processed meats, salty foods, sweet foods }\end{array}$ & $68 \cdot 3$ & $72 \cdot 3$ & 63.9 \\
\hline $\begin{array}{l}\text { Recommendation 24: To prevent infant botulism, do } \\
\text { not use honey in the feeding of infants less than } \\
1 \text { year of age }\end{array}$ & 16. Followed Recommendation $24 \ddagger, \S$ & 94.7 & $96 \cdot 3$ & $92 \cdot 8$ \\
\hline \multirow[t]{2}{*}{ All recommendations listed in this table } & $\begin{array}{l}\text { 17. Followed all recommendations listed above, } \\
\text { including exclusive breast-feeding to } 6 \text { months }\end{array}$ & $1 \cdot 8$ & 3.6 & 0 \\
\hline & $\begin{array}{l}\text { 18. Followed all recommendations listed above, } \\
\text { with the exception that mothers } \\
\text { supplemented breast milk with formula before } \\
6 \text { months (no other liquids or solids given } \\
\text { before } 6 \text { months) }\end{array}$ & $4 \cdot 9$ & $9 \cdot 6$ & 0 \\
\hline
\end{tabular}

NHTI, Nutrition for Healthy Term Infants; CFG, Canada's Food Guide; N/A, not applicable.

Significant difference between groups: ${ }^{\star} P<0.05,{ }^{\star \star \star} P<0.001$.

†Note that the most recent recommendations recognize that a soya-based commercial infant formula may be given for cultural, religious or health reasons ${ }^{(31)}$. ¥The denominator is 301 as twenty-four mothers did not complete the 12 month survey and thus foods given between 6 and 12 months could not be determined. §Although other milks are not recommended for the first 2 years of life, the Infant Feeding survey covered only the first 12 months.

IIThe denominator is 324 as one mother's breast-feeding status could not be defined at 6 months. 
recommended foods, regardless of the age at which these foods were introduced ( $92.9 \%)$.

Mothers who were not breast-feeding at 6 months were significantly more likely than breast-feeding mothers to introduce complementary foods prior to the recommended age of 6 months. Specifically, they were more likely to introduce water and juice before 6 months, to give their infants beverages not recommended in the NHTI, to provide inappropriate types of milk within the first year, to provide infant cereals, vegetables and fruit before 6 months, and to give foods not recommended by CFG (e.g. foods that are high in sugar and salt). No other statistically significant differences in following the recommendations emerged between breast-feeding and non-breast-feeding mothers.

Other than exclusive breast-feeding, recommendations with the lowest adherence included supplementing with vitamin D for breast-fed infants at 6 months $(58.4 \%$ of breast-feeding mothers complied), avoiding foods not recommended in the CFG (e.g. soft drinks, cookies, processed meats, salty or sweet snacks; $68.3 \%$ of mothers complied) and providing types of milk appropriate to the infant's age ( $82.4 \%$ of mothers complied).

\section{Objective 2: Describe first complementary foods and investigate differences by breast-feeding status}

Figure 1 shows the distribution of infant age at which liquids only, solids only, and either liquids or solids were first introduced. Figure 2 provides a graphical representation of the introduction of complementary foods by food group and the breast-feeding status of the mother. In Figs 1 and 2 the 'first' introduction refers to the time at which infants were introduced more than once to foods in each food group. Mothers who were not breast-feeding at 6 months introduced complementary foods significantly earlier (median introduction $=16$ weeks) than mothers who were breast-feeding to any extent at 6 months (median introduction $=22$ weeks, $P<0 \cdot 001$; Table 3). Results in Fig. 2 indicate that mothers who were in the any breast-feeding group at 6 months introduced other grains, vegetables and fruit, water and foods not recommended in CFG significantly later than women who were not breast-feeding at 6 months. It is noteworthy that several women introduced solids or liquids before their infant was 2 months of age, more than 4 months earlier than recommended.

\section{Objective 3: Examine whether any breast-feeding is associated with earlier introduction to complementary foods relative to non-breast- feeding, after controlling for potentially confounding factors}

Table 4 presents the results of a Cox proportional hazards model examining the association between time to introduction of complementary foods and breast-feeding status, while controlling for infant birth weight and maternal age, parity, smoking and prenatal/breast-feeding class attendance. Results indicate that at any time point prior to 6 months for mothers who had not already introduced complementary foods to their infants, non-breast-feeding mothers were twice as likely as breast-feeding mothers to introduce complementary foods (hazard ratio $=2 \cdot 0,95 \%$ CI $1.6,2 \cdot 6, P<0.001)$. In addition, younger mothers (hazard ratio $=1 \cdot 9,95 \% \mathrm{CI} 1 \cdot 2,2 \cdot 9, P=0.003$ ), first-time mothers (hazard ratio $=1 \cdot 3,95 \%$ CI $1 \cdot 0,1 \cdot 7, P=0 \cdot 04$ ) and mothers who smoked (hazard ratio $=1 \cdot 8,95 \%$ CI $1 \cdot 2,2 \cdot 7$, $P=0.008)$ introduced complementary foods earlier, regardless of breast-feeding status.

\section{Objective 4: Determine needs for improvements in timing and resources of interventions by examining breast-feeding rates over time and information sources used by mothers}

Earlier results indicated that the timing of the introduction of complementary foods is linked to breast-feeding status. Breast-feeding trends were, therefore, examined to provide insight into the optimal time to provide additional support to families with new infants. Trends during the first

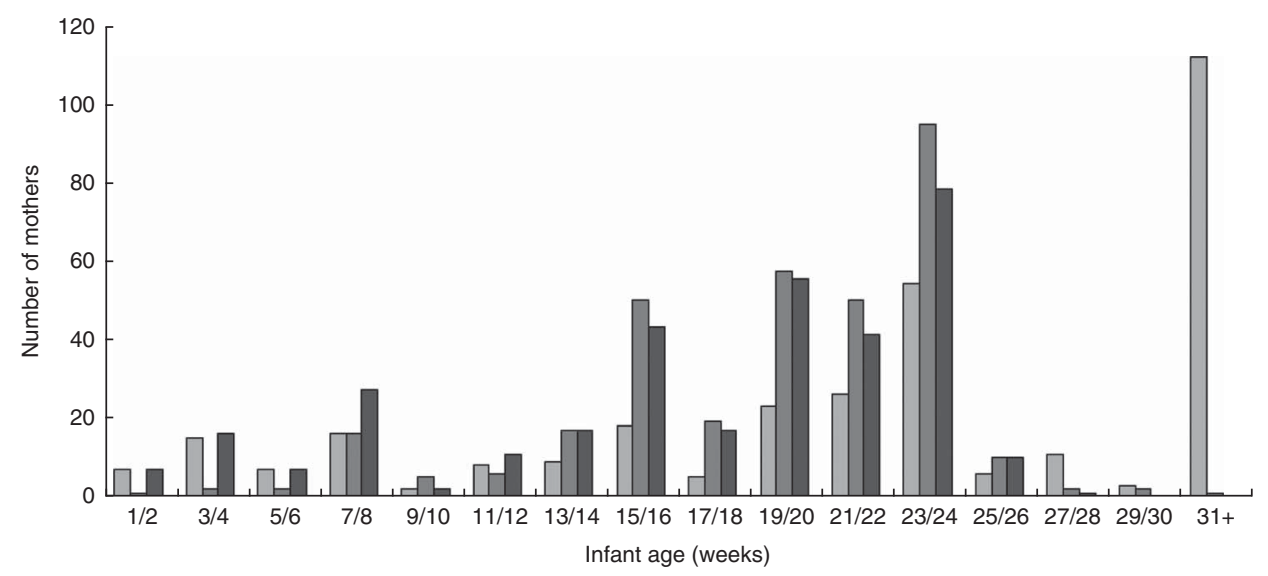

Fig. 1 Distribution of infant age at which liquids only $(\square)$, solids only ( $\square$ ), and either liquids or solids ( $\square$ ) were first introduced; Kingston, Frontenac, and Lennox \& Addington (KFL\&A) Infant Feeding Survey, Ontario, Canada, 2008 


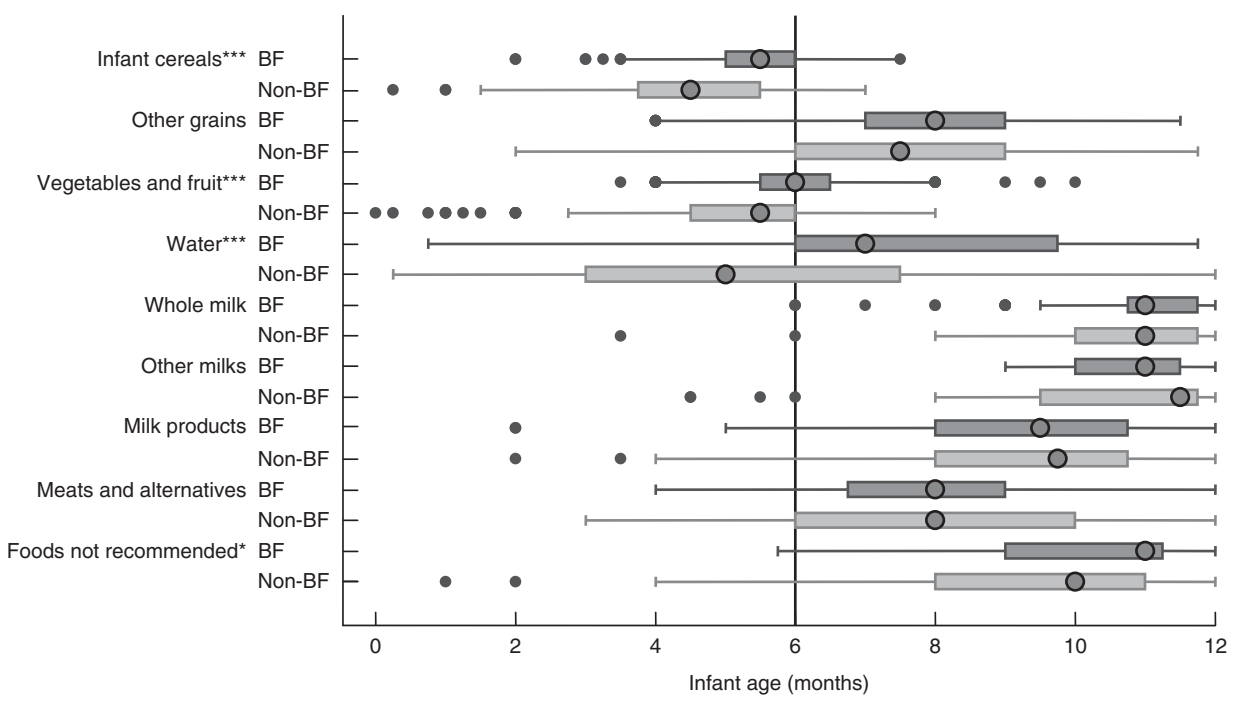

Fig. 2 First introduction to complementary foods by breast-feeding (BF) status ( $\square$, BF; $\square$, non-BF) at 6 months; Kingston, Frontenac, and Lennox \& Addington (KFL\&A) Infant Feeding Survey, Ontario, Canada, 2008. Data are presented as box-andwhisker plots in which the large circle indicates the median age at first introduction; the left and right edge of the box represent the 25th and 75th percentile, respectively (i.e. interquartile range); the left and right whisker represent the minimum and maximum age at first introduction, respectively; and small dots indicate the outliers. Non-BF includes mothers who were not breast-feeding when infant was 6 months old and BF includes mothers who were breast-feeding to any extent ('any breast-feeding') when infant was 6 months old. Significant difference between groups: ${ }^{\star} P<0.05$, ${ }^{\star \star \star} P<0.001$

Table 3 Median time of first introduction of solids and liquids by breast-feeding status at 6 months; Kingston, Frontenac, and Lennox \& Addington (KFL\&A) Infant Feeding Survey, Ontario, Canada, 2008

\begin{tabular}{lccc}
\hline & $\begin{array}{c}\text { Median time of first } \\
\text { liquid introduction }\end{array}$ & $\begin{array}{c}\text { Median time of first } \\
\text { solid introduction }\end{array}$ & $\begin{array}{c}\text { Median time of first liquid/ } \\
\text { solid introduction }\end{array}$ \\
\hline Any breast-feeding at 6 months & 28 weeks ${ }^{\star \star \star}$ & 22 weeks & 18 weeks \\
Non-breast-feeding at 6 months & 20 weeks & 18 weeks & 16 weeks \\
\hline
\end{tabular}

Significant difference between groups: ${ }^{* \star} P<0.001$.

Table 4 Cox proportional hazards model examining associations of breast-feeding status with time to introduction to complementary foods in infants prior to age 6 months, after controlling for other variables ( $n$ 325); Kingston, Frontenac, and Lennox \& Addington (KFL\&A) Infant Feeding Survey, Ontario, Canada, 2008

\begin{tabular}{|c|c|c|c|c|c|}
\hline Independent variable & Hazard ratio & SE & Lower $95 \% \mathrm{Cl}$ & Upper $95 \% \mathrm{Cl}$ & $P>\chi^{2}$ \\
\hline \multicolumn{6}{|l|}{ Mother's age } \\
\hline $15-24$ years & 1.9 & 0.42 & $1 \cdot 2$ & $2 \cdot 9$ & $0.003^{\star \star}$ \\
\hline 25-34 years & $1 \cdot 2$ & 0.19 & 0.9 & $1 \cdot 7$ & $0 \cdot 18$ \\
\hline$\geq 35$ years & - & - & - & - & - \\
\hline \multicolumn{6}{|c|}{ Smoking during pregnancy } \\
\hline Yes & $1 \cdot 8$ & 0.38 & $1 \cdot 2$ & $2 \cdot 7$ & $0.008^{\star \star}$ \\
\hline No & - & - & - & - & - \\
\hline \multicolumn{6}{|c|}{ Mother attended breast-feeding or prenatal class } \\
\hline No & 1.3 & 0.16 & 1.0 & 1.6 & 0.06 \\
\hline Yes & - & - & - & - & - \\
\hline \multicolumn{6}{|l|}{ Parity } \\
\hline 1 child & $1 \cdot 3$ & 0.16 & 1.0 & 1.7 & $0.04^{*}$ \\
\hline$\geq 2$ children & - & - & - & - & - \\
\hline \multicolumn{6}{|l|}{ Infant birth weight } \\
\hline $1500-2499 \mathrm{~g}$ & 0.6 & 0.24 & 0.3 & 1.3 & 0.2 \\
\hline $2500-3999 \mathrm{~g}$ & 0.9 & 0.15 & 0.7 & $1 \cdot 2$ & 0.5 \\
\hline$\geq 4000 \mathrm{~g}$ & - & - & - & - & - \\
\hline \multicolumn{6}{|l|}{ Breast-feeding status } \\
\hline Non-breast-feeding & $2 \cdot 0$ & 0.26 & $1 \cdot 6$ & $2 \cdot 6$ & $<0.001^{\star \star \star}$ \\
\hline Any breast-feeding & - & - & - & - & - \\
\hline
\end{tabular}

- indicative of comparison group.

${ }^{\star} P<0.05,{ }^{\star \star} P<0.01,{ }^{\star \star \star} P<0.001$. 


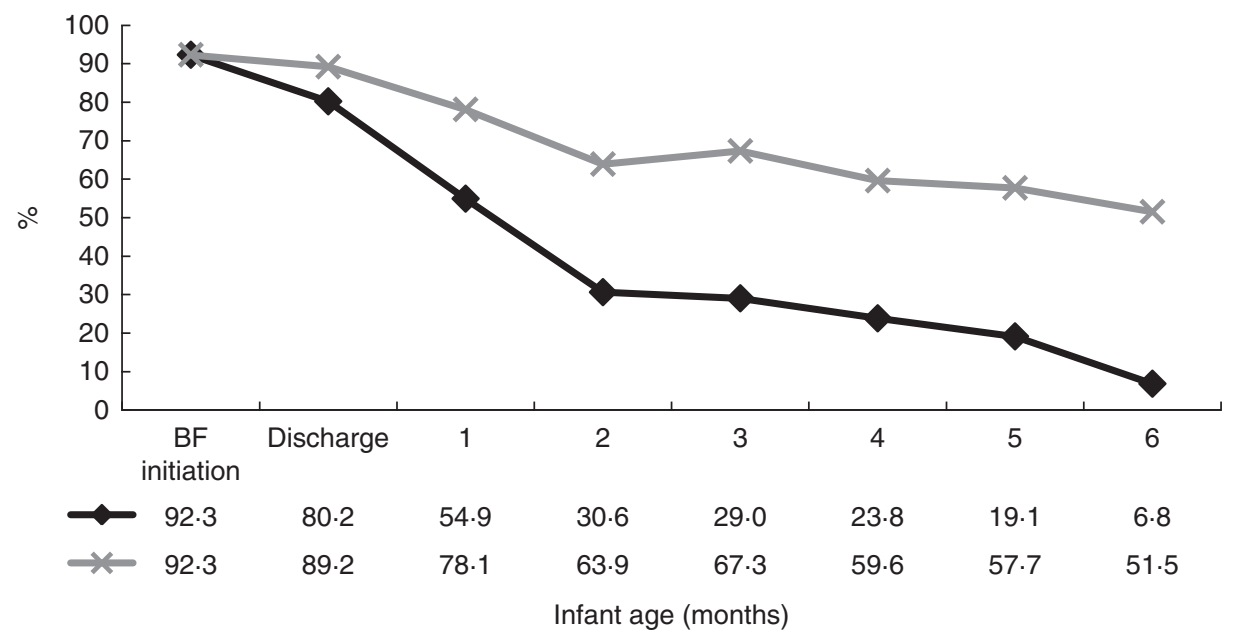

Fig. 3 Breast-feeding trends during the first 6 months after birth $(\smile$, exclusive breast-feeding from birth; $\varkappa$, any breastfeeding); Kingston, Frontenac, and Lennox \& Addington (KFL\&A) Infant Feeding Survey, Ontario, Canada, 2008

Table 5 Sources mothers used and ranked as most useful to obtain information on introducing complementary foods to their infant; Kingston, Frontenac, and Lennox \& Addington (KFL\&A) Infant Feeding Survey, Ontario, Canada, 2008

\begin{tabular}{|c|c|c|c|c|}
\hline Source & $\begin{array}{l}\text { No. of mothers } \\
\text { who used source } \\
(n 301)\end{array}$ & $\begin{array}{c}\text { Percentage of } \\
\text { mothers who used } \\
\text { source† }(n 301)\end{array}$ & $\begin{array}{c}\text { Top five most } \\
\text { useful } \\
\text { sources: rank }\end{array}$ & $\begin{array}{c}\text { Top five most } \\
\text { useful } \\
\text { sources: \% }\end{array}$ \\
\hline Public health nurse & 174 & $57 \cdot 8$ & 1 & 23.0 \\
\hline Hospital & 133 & $44 \cdot 2$ & 4 & $12 \cdot 0$ \\
\hline Doctor & 106 & $35 \cdot 2$ & 5 & $11 \cdot 0$ \\
\hline Books/magazines & 101 & $31 \cdot 1$ & 2 & $14 \cdot 0$ \\
\hline Internet & 90 & $29 \cdot 9$ & 3 & $13 \cdot 0$ \\
\hline Information provided with free formula samples & 86 & $28 \cdot 6$ & & \\
\hline Videos/pamphlets & 69 & 22.9 & & \\
\hline Family/friends & 37 & $12 \cdot 3$ & & \\
\hline Breast-feeding or well baby clinic & 13 & $4 \cdot 3$ & & \\
\hline Nurse at doctor's office & 10 & 3.3 & & \\
\hline Nutritionist or dietitian & 10 & $3 \cdot 3$ & & \\
\hline Family/home visitor (not public health nurse) & 9 & 3.0 & & \\
\hline Parenting classes & 7 & $2 \cdot 3$ & & \\
\hline Other & 37 & $12 \cdot 3$ & & \\
\hline
\end{tabular}

†Mothers were allowed to provide more than one option, thus the percentages total greater than $100 \%$. The percentage shown uses the denominator of all mothers who answered this question.

6 months after birth can be seen in Fig. 3. Results indicate that the percentage of mothers exclusively breast-feeding dropped sharply in the first 2 months. Rates of exclusive breast-feeding dropped from $80.2 \%$ at discharge to $30.6 \%$ at 2 months, and rates of any breast-feeding dropped from $89.2 \%$ to $63.9 \%$. The percentage of women in the any breast-feeding group remained fairly steady from 2 to 6 months $(63.9 \%$ to $51.5 \%)$. Efforts to promote both exclusive and any breast-feeding should, therefore, be geared toward mothers with infants younger than 2 months.

The sources most often used by mothers to obtain information on introducing complementary foods were investigated to determine potential avenues for public health intervention. Public health nurses were reported most frequently ( $57.8 \%$ ), followed by hospitals ( $44.2 \%$ ), doctors $(35.2 \%)$, books/magazines $(31.1 \%)$ and the Internet $(29.9 \%)$. Mothers in the any breast-feeding group were more likely than mothers in the non-breast-feeding group to use public health nurses and books to access information regarding introduction to complementary foods. When asked which sources were most useful, the top five were ranked as follows: (i) public health nurses (23.0\%); (ii) books/magazines (14.0\%); (iii) the Internet (13.0\%); (iv) hospitals (12.0\%); and (v) doctors (11.0\%; Table 5). No differences in the usefulness of resources emerged between breast-feeding and non-breast-feeding mothers. Therefore, these sources appear to be most promising when deciding where to direct interventions to promote NHTI recommendations.

\section{Discussion}

In the present study, fewer than $2 \%$ of mothers followed all NHTI recommendations and only $19.4 \%$ of mothers waited until 6 months to introduce complementary foods. 
The latter finding is supported by previous work ${ }^{(11,14,27)}$. The present study adds to this body of literature, however, by investigating other, less commonly addressed NHTI recommendations. For example, $45.2 \%$ of mothers introduced liquids other than breast milk or formula (most commonly water or fruit juices) before 6 months. These other liquids may compromise adequate intake of nutrients and increase health-related risks, including dental caries and nursing bottle syndrome ${ }^{(28)}$. Results also indicate that almost a third of mothers introduced complementary food items not listed in the CFG to their infant before 1 year of age. The present study did not assess the quantity of these food items fed to infants, but it is recommended that foods with high salt and sugar content be avoided, as they may interfere with the nutritious energy-dense foods needed for rapid growth. Limiting these foods items also allows the infant to experience natural food flavours and helps to promote lifelong eating habits ${ }^{(31)}$. Lastly, over $40 \%$ of breast-fed infants were not supplemented with vitamin D, which is lower than reported in previous studies ${ }^{(33,34)}$, and necessary for infant health as breast milk is not a dependable source of this nutrient ${ }^{(28)}$.

Despite low adherence to several recommendations, it is promising that some foods are introduced in the appropriate order, with iron-fortified foods (i.e. infant cereals) fed first or in the same week as other foods. Introducing iron-rich foods first is encouraged to promote infant growth and development, and to reduce the risk of long-term health effects caused by iron deficiency in infancy $^{(3)}$. More effort is needed to promote the earlier introduction of meat and meat alternatives, since these were not common first foods. Meat and meat alternatives are advised alongside iron-fortified cereals due to their high iron content and the benefits obtained from haem iron contained in meat, poultry and fish ${ }^{(3)}$.

No previous research, to our knowledge, has examined differences in the introduction of various foods by breastfeeding status. Consistent with other studies, vegetables and fruit (including juice), water and infant cereals were introduced earliest to all infants ${ }^{(12,35)}$. However, it is noteworthy that the present study found that mothers who did not breast-feed to 6 months introduced these food items sooner than mothers breast-feeding at 6 months. The early introduction of water, especially prior to other foods and liquids, has important implications, since it offers no nutritional value and, similar to other foods, may satiate the infant and reduce intake of breast milk. In addition, mothers who did not breast-feed at 6 months were more likely to provide their infants with non-recommended beverages and inappropriate types of milk within the first year. They also provided foods that are high in sugar and salt significantly earlier than mothers who breast-fed to any extent at 6 months. These foods should be avoided due to their low nutritional value and to help the infant establish lifelong healthy eating habits ${ }^{(35)}$. No significant differences were found between breast-feeding and non-breast-feeding mothers with regard to the other food categories. Thus, not all food groups are introduced earlier in mothers who do not breast-feed at 6 months, and special attention must be paid to delaying the introduction and frequency of these particular liquids and solids in infants of non-breast-feeding mothers.

Overall, mothers who did not breast-feed to 6 months introduced complementary foods to their infants significantly earlier than mothers who breast-fed to any extent at 6 months, even when accounting for sociodemographic, infant and maternal characteristics. Previous research has also reported breast-feeding as an indicator of the timelier introduction of complementary foods ${ }^{(11,15-24)}$. The control of confounders was critical to the interpretation of results to ensure that differences observed by breast-feeding status could not be explained by known confounders in this particular sample. Since the present study was observational, not a controlled experiment, the possibility that the relationship revealed may be subject to residual confounding by unobserved sociodemographic factors cannot be completely ruled out. There is not, however, concrete evidence of existence of such sociodemographic factors that may confound the relationship based on a review of the literature on this topic. Without knowing the reasons for initiating complementary foods in the study, it is difficult to explain this association. A recent study investigated whether breast-feeding and formula-feeding mothers differed in their reasons for introducing complementary foods and found that mothers who formula feed may be starting complementary foods earlier on the advice of health-care professionals $^{(36)}$. This suggests that women who formula feed need to be made aware that formula is adequate nutrition until their infant is 6 months of age.

In examining breast-feeding trends and the introduction of complementary foods, it is evident that greater support for mothers is needed prior to 2 months in order to promote exclusive breast-feeding, and from 2 to 4 months in order to promote the delayed introduction to complementary foods. The greatest decline in rates of exclusive and any breastfeeding were seen prior to 2 months in the current sample whereas complementary foods were introduced among non-breast-feeding and breast-feeding mothers at approximately 4 months and 5.5 months, respectively. Previous research has reported similar timing in terms of declines in breast-feeding ${ }^{(37)}$ and differences in early introduction to complementary foods by breast-feeding status ${ }^{(27,36)}$. It may be useful to target sources already used by mothers to access information regarding introducing complementary foods. Mothers reported using public health nurses, hospitals and doctors most often to gain this information, and also cited these sources as very useful. Mothers who breast-fed to any extent at 6 months were more likely than non-breastfeeding mothers to report use of public health nurses and books to gain information. Of potential concern is that previous research indicates that mothers may be receiving unclear or inconsistent advice from health-care professionals 
regarding infant feeding recommendations ${ }^{(38)}$. It is imperative that health-care professionals provide consistent, evidence-based and up-to-date information, and that they be educated on ways to encourage mothers to overcome barriers to adherence ${ }^{(38)}$. Effort should be made to ensure that support from public health nurses continues to be available to mothers after they stop breast-feeding.

It should be noted that in order for a mother to follow the NHTI recommendations, she must be aware of and agree with them $^{(15,27)}$. There are a number of programmes and services that public health can offer to increase mothers' knowledge, agreement and self-efficacy in adhering to the recommendations, and several health units across Ontario do so. For example, KFL\&A Public Health offers breast-feeding clinics, 'introduction to solids' classes and programmes to support families from the prenatal period until the transition to school. Greater effort is needed to ensure that other NHTI recommendations, such as vitamin D supplementation, are also promoted through public health. As far as timing of programmes and services, early infancy appears to be a critical period to promote adherence to recommendations. Effort should be made to ensure higher enrolment in existing programmes by reducing barriers to access and targeting vulnerable populations. As indicated by the present results, for example, interventions should target mothers who do not breast-feed to any extent, are younger, smoke during pregnancy, are first-time mothers and have not attended a prenatal class. Finally, it is important to foster a primary care and public health partnership to ensure consistent messaging across health settings and to assist in addressing the educational and resource needs of primary care. It is likely that combined support and resources from public health, primary care and other health services will be needed to increase knowledge, skill level, self-efficacy and adherence to the NHTI recommendations.

\section{Limitations}

Several limitations for the present study should be noted. First, Infant Feeding Survey participants were older, more educated and of higher socio-economic status than the general population of women giving birth in the region. Previous research indicates that mothers with these characteristics are more likely to breast-feed and to follow infant feeding recommendations ${ }^{(11,16,25,27,39,40)}$. This suggests that the proportion of mothers who do follow the infant feeding recommendations is less than that found in the current study, and therefore the need for guidance and support in following the recommendations is expected to be even greater than is evident here.

Second, the sample size was relatively small and almost $30 \%$ of the initial study sample was lost to follow-up at 6 months. Of the 463 mothers who met the inclusion criteria and agreed to participate at the beginning of the Infant Feeding Survey, only 325 mothers provided adequate data for the current analyses. The small sample size prohibited us from classifying breast-feeding type into exclusive breast-feeding, mixed feeding and formula only. Instead, 'any breast-feeding' and 'non-breast-feeding' categories were used.

Third, introduction of complementary foods and breastfeeding status were measured using self-report, thereby introducing the potential for reporting bias. The questionnaire items that assessed introduction of complementary foods were developed by the Reproductive Health Team, including a public health dietitian, at KFL\&A Public Health, but its validity was not evaluated.

Fourth, there are some limitations associated with using NHTI's recommended 6-month cut-off for introducing complementary foods. Although 6 months is a guideline, it is recognized that some infants may safely be ready for complementary foods slightly earlier or later than this ${ }^{(28)}$. It is unclear what the clinical implications are of introducing foods slightly before the recommended 6-month period (e.g. at 5.5 months) or introducing non-recommended foods in very small quantities before the recommended age. More work is needed to investigate the implications of not following recommendations exactly.

Lastly, the Infant Feeding Survey did not ask why women initiated complementary foods; thus, we are unable to examine the reasons for mothers' decisions to introduce complementary foods early. Future research could be conducted in this area to help determine effective interventions.

\section{Conclusion}

There is evidence of a significant need for public health efforts to encourage optimal infant feeding. By examining the recommendations individually, and comparing feeding practices by breast-feeding status, we were able to highlight certain recommendations and target populations that should receive extra attention through public health initiatives. Encouragement of breast-feeding and introducing foods at the recommended times are important, but several other NHTI recommendations also require attention. Both breast-feeding and non-breast-feeding mothers are in need of support, and it is suggested that interventions target mothers with infants less than 2 months of age and through common points of access.

\section{Acknowledgements}

Acknowledgements: The authors would like to acknowledge Tracy McDonough, a public health dietitian at KFL\&A Public Health, for providing insight into implications from study results and feedback on manuscript drafts. Financial support: This research received no specific grant from any funding agency in the public, commercial or not-for-profit sectors. Conflict of interest: None. Authorship: S.F., K.S.O. 
and E.B. formulated the research questions. S.F. and Y.P. analysed the data. E.B., S.F. and K.S.O. wrote the first draft of the article. All authors edited and contributed to the final draft. Ethics of buman subject participation: This study was conducted according to the guidelines laid down in the Declaration of Helsinki and all procedures involving human subjects/patients were approved by the Queen's University and Associated Teaching Hospitals Research Ethics Board.

\section{References}

1. World Health Organization \& UNICEF (2003) Global Strategy for Infant and Young Child Feeding. Geneva: WHO.

2. Health Canada (2004) Exclusive Breastfeeding Duration: 2004 Health Canada Recommendation. http://www.breast feedingalberta.ca/files/exclusive_breastfeeding_duration_e.pdf (accessed January 2015).

3. Health Canada, Canadian Paediatric Society, Dietitians of Canada et al. (2012) Nutrition for Healthy Term Infants: Recommendations from Birth to Six Months. http://www. hc-sc.gc.ca/fn-an/nutrition/infant-nourisson/recom/indexeng.php (accessed January 2015).

4. Moss BG \& Yeaton WH (2014) Early childhood healthy and obese weight status: potentially protective benefits of breastfeeding and delaying solid foods. Matern Child Health J 18, 1224-1232.

5. Tarini BA, Carroll AE, Sox CM et al. (2006) Systematic review of the relationship between early introduction of solid foods to infants and the development of allergic disease. Arch Pediatr Adolesc Med 160, 502-507.

6. Rosenbauer J, Herzig P, Kaiser P et al. (2007) Early nutrition and risk of type 1 diabetes mellitus - a nationwide casecontrol study in preschool children. Exp Clin Endocrinol Diabetes 115, 502-508.

7. Gaffney KF, Kitsantas P \& Cheema J (2012) Clinical practice guidelines for feeding behaviors and weight-for-age at 12 months: a secondary analysis of the Infant Feeding Practices Study II. Worldviews Evid Based Nurs 9, 234-242.

8. Huh SY, Rifas-Shiman SL, Taveras EM et al. (2011) Timing of solid food introduction and risk of obesity in preschoolaged children. Pediatrics 127, e544-e551.

9. Yan J, Liu L, Zhu Y et al. (2014) The association between breastfeeding and childhood obesity: a meta-analysis. BMC Public Health 14, 1267.

10. Vehapoglu A, Yazici M, Demir AD et al. (2014) Early infant feeding practice and childhood obesity: the relation of breast-feeding and timing of solid food introduction with childhood obesity. J Pediatr Endocrinol Metab 27, 1181-1187.

11. Briefel RR, Reidy K, Karwe V et al. (2004) Feeding infants and toddlers study: improvements needed in meeting infant feeding recommendations. J Am Diet Assoc 104, 1 Suppl. 1, S31-S37.

12. Friel JK, Hanning RM, Isaak CA et al. (2010) Canadian infants' nutrient intakes from complementary foods during the first year of life. BMC Pediatr 10, 43.

13. Nadler E (2007) Region of Waterloo Public Health Infant Feeding Survey 2006/2007. http://chd.region.waterloo.on.ca/ en/researchResourcesPublications/resources/InfantFeeding Study.pdf (accessed April 2015).

14. Tatone-Tokuda F, Dubois L \& Girard M (2009) Psychosocial determinants of the early introduction of complementary foods. Health Educ Behav 36, 302-320.

15. Caton SJ, Ahern SM \& Hetherington MM (2011) Vegetables by stealth. An exploratory study investigating the introduction of vegetables in the weaning period. Appetite 57, 816-825.

16. Coleman BL, Gutmanis I, Larsen LL et al. (2009) Introduction of solid foods: do mothers follow recommendations? Can J Diet Pract Res 70, 135-140.

17. Dubois L \& Girard M (2003) Social inequalities in infant feeding during the first year of life. The Longitudinal Study of Child Development in Quebec (LSCDQ 1998-2002). Public Health Nutr 6, 773-783.

18. Giovannini M, Riva E, Banderali G et al. (2004) Feeding practices of infants through the first year of life in Italy. Acta Paediatr 93, 492-497.

19. Hamlyn B, Brooker S, Oleinikova S et al. (2002) Infant Feeding 2000. A survey conducted on behalf of the Department of Health, the Scottish Executive, the National Assembly for Wales and the Department of Health Social Services and Public Safety in Northern Ireland. http:// webarchive.nationalarchives.gov.uk/+/www.dh.gov.uk/en/ Publicationsandstatistics/Publications/PublicationsStatistics/ DH_4079223 (accessed January 2015).

20. Hendricks K, Briefel R, Novak T et al. (2006) Maternal and child characteristics associated with infant and toddler feeding practices. J Am Diet Assoc 106, 1 Suppl. 1, S135-S148.

21. Kuo AA, Inkelas M, Slusser WM et al. (2011) Introduction of solid food to young infants. Matern Child Health J 15, $1185-1194$.

22. Kwavnick BS, Reid DJ, Joffres MR et al. (1999) Infant feeding practices in Ottawa-Carleton: the introduction of solid foods. Can J Public Health 90, 403-407.

23. Lande B, Andersen LF, Baerug A et al. (2003) Infant feeding practices and associated factors in the first six months of life: the Norwegian infant nutrition survey. Acta Paediatr 92, $152-161$.

24. Wright CM, Parkinson KN \& Drewett RF (2004) Why are babies weaned early? Data from a prospective population based cohort study. Arch Dis Child 89, 813-816.

25. Schiess S, Grote V, Scaglioni S et al. (2010) Introduction of complementary feeding in 5 European countries. $J$ Pediatr Gastroenterol Nutr 50, 92-98.

26. Schwartz C \& Evers S (1998) Infant feeding practices in low income communities in Ontario. J Can Diet Assoc 50, 92-98.

27. Scott JA, Binns CW, Graham KI et al. (2009) Predictors of the early introduction of solid foods in infants: results of a cohort study. BMC Pediatr 9, 60.

28. Canadian Paediatric Society, Dietitians of Canada \& Health Canada (1998) Nutrition for Healthy Term Infants. Ottawa: Minister of Public Works and Government Services, Canada.

29. KFL\&A Public Health (2011) Feeding Practices of Infants in the Kingston, Frontenac, Lennox \& Addington Area During the First Year of Life. Kingston, ON: KFL\&A Public Health.

30. Health Canada (2007) Eating Well with Canada's Food Guide. http://hc-sc.gc.ca/fn-an/food-guide-aliment/indexeng.php (accessed January 2015).

31. Klein JP \& Moeschberger ML (2003) Survival Analysis, Techniques for Censored and Truncated Data. New York: Springer.

32. Health Canada, Canadian Paediatric Society, Dietitians of Canada et al. (2014) Nutrition for Healthy Term Infants: Recommendations from Six to 24 Months. http:// www.hc-sc.gc.ca/fn-an/nutrition/infant-nourisson/recom/ recom-6-24-months-6-24-mois-eng.php (accessed January 2015).

33. Gallo S, Jean-Philippe S, Rodd C et al. (2010) Vitamin D supplementation of Canadian infants: practices of Montreal mothers. Appl Physiol Nutr Metab 35, 303-309.

34. Crocker B, Green TJ, Barr SI et al. (2011) Very high vitamin D supplementation rates among infants aged 2 months in 
Vancouver and Richmond, British Columbia, Canada. BMC Public Health 11, 905.

35. Grummer-Strawn LM, Scanlon KS \& Fein SB (2008) Infant feeding and feeding transitions during the first year of life. Pediatrics 122, Suppl. 2, S36-S42.

36. Clayton HB, Li R, Perrine CG et al. (2013) Prevalence and reasons for introducing infants early to solid foods: variations by milk feeding type. Pediatrics 131, e1108-e1114.

37. Brown CR, Dodds L, Attenborough R et al. (2013) Rates and determinants of exclusive breastfeeding in first 6 months among women in Nova Scotia: a population-based cohort study. CMAJ Open 1, E9-E17.

38. Arden MA (2010) Conflicting influences on UK mothers' decisions to introduce solid foods to their infants. Matern Child Nutr 6, 159-173.

39. Alder EM, Williams FL, Anderson AS et al. (2004) What influences the timing of the introduction of solid food to infants? Br J Nutr 92, 527-531.

40. Pfluger M, Winkler C, Hummel S et al. (2010) Early infant diet in children at high risk for type 1 diabetes. Horm Metab Res 42, 143-148. 